\title{
СЫПОСТАВИТЕЛНА СЬЧЕТАЕМОСТ
}

\author{
Димитър ВЕСЕЛИНОВ, Милена ЙОРДАНОВА \\ Софийски университет „Св. Климент Охридски“ \\ E-mail: d_vesselinov@yahoo.fr; yordanova_milena@yahoo.com
}

\section{COMPARATIVE COMPATIBILITY \\ Dimitar VESSELINOV, Milena YORDANOVA}

\author{
Sofia University "St. Kliment Ohridski" \\ E-mail: d_vesselinov@yahoo.fr; yordanova_milena@yahoo.com
}

\begin{abstract}
The article discusses the problem of comparative compatibility in Bulgarian, French and Turkish languages. The first two languages are Indo-European but from different groups (the Slavic and the Romance groups respectively), and the third is a non-Indo-European, representative of the Turkic language family. The objective of this study are the cognitive and pragmatic chains for expressing the impossibility of boarding a certain vehicle due to its delayed arrival at the place of departure, which are characteristic of the linguistic pictures of the three languages in question. The purpose of the study is to identify the elements used for building these cognitive and pragmatic chains in Bulgarian, French and Turkish languages by comparing them and exploring their potential for combinations in the languages mentioned. Samples of everyday speech acts from the three languages have been presented, described, juxtaposed, compared and analyzed from a morphosyntactic, lexical and pragmatic perspective. A combination of the comparative method and matrix modelling is used for processing the linguistic material and the results are presented in a tabular form. The conclusion not only reveals some linguistic differences, but suggests that they are due to the cultures of the three countries and their transport systems. A suggestion for further implementation of the results of the study is made, namely, elaborating bilingual and/or multilingual dictionaries.
\end{abstract}

KEYWORDS: inter-language cognitive chain, inter-language pragmatic chain, French language, Bulgarian language, Turkish language, miss the train.

Спецификата на естествената комуникативна дейност е такава, че отделните речеви изкази не предопределят стопроцентово начините на тяхната интерпретация от съответните участници в комуникативния акт. По принцип всеки речеви изказ съдържа позоваване на реалност, която за съжаление не е експлицитно унилатерално езиково кодирана. Даден изказ може да бъде възприет буквално, широко контекстуално или направо преносно, тъй като конструирането му от говорещия няма реалния потенциал да предопредели максимално точно визираната интерпретация. Според теорията за уместността на изказа на Спербер и Уилсон говорещият може донякъде да кодира когнитивни ориентири, които евентуално да помогнат на неговия събеседник да го разбере правилно или поне да му укаже посоката за визираното интерпретиране (Wilson, Sperber, 2012, p. 31, 47). Неслучайно функционалната роля на езика се състои не в елементарното кодиране и предаване на информация, а в „създаването на кооперативна област на взаимодействие между говорещите чрез изработване на обща система за отчитане“ (Матурана, 1996, с. 140), която ще подпомогне взаимното разбиране. Такива „системи за отчитане“ са многоезичните сьпоставителни модели, чието лексикално матрично запълване илюстрира разликите между националните картини на света и разликите в изграждането на прагматични интерпретации. В случая те могат да се разглеждат като когнитивни и прагматични вериги, илюстриращи различни речеви ситуации в монолингвален и мултилингвален план.

Класическият пример за изграждането на когнитивно-прагматична интерпретационна верига в динамично променящата се комуникативна реалност е станалото банално оправдаване за дадено закъснение с изпуснатия влак, което е характерно явление и за трите изследвани езика. Ако служител се извини пред началника си с изказа „Изпуснах влака“ в повечето случаи ще бъде възприет буквално, стига това да не е повтаряща се практика. Ако обаче син (или дъщеря) използва това извинение след закъснение от няколко часа, загрижените родители биха си задали въпроса преди всичко какво е правил(а), докато дойде следващият влак. В случай че изразът е употребен пред ревнив съпруг, то е много вероятно той да си зададе въпроса дали жена му е 
направила усилие да се качи въобще на влака или си търси правдоподобно извинение ${ }^{1}$. Накратко в комуникационния процес се формулират и изказват интенции, които трябва да бъдат уловени и адекватно декодирани, като сред възможните им интерпретации се избере тази, която е контекстуално мотивирана и доближаваща се до замисъла на говорещия. В този контекст сьпоставителната лексикалната съчетаемост (валентност, колокативност) и езиковото отразяване на етномаркираната картина на света съвсем естествено попадат в полезрението на лингводидактическата интерпретация.

Конструирането на междуезикови прагматични и когнитивни вериги е важно за разкриването на начините на функциониране на дадена езикова система и за оптимизиране на нейното успешно овладяване. Пример за подобно конструиране на междуезикови прагматикокогнитологични комбинаторни вериги са каузално-когнитивните изрази за назоваване на „идеята за изпускане на превозно средство поради закъснение“ съответно във френския, в българския и в турския език. Ключовият темпорален елемент в тази ситуация е моментът на тръгване на даденото превозно средство, който е независим по отношение на субекта на действието, тъй като превозното средство е обществено и часът на тръгване е определен от договореност, с която ползвателят е дльжен да се съобразява и спазва. Вторият елемент в тази ситуация е точното фиксирано място на тръгване, което обикновено е гара (перон), спирка (автобусна, жп), пристанище (кей), летище (изход, гейт), метростанция и др., независимо че в изразите със семантика 'изпускам превозно средство' то е имплицитно и предполага съответен запас от фонови познания.

Във френския език един от най-разпространените глаголи за отбелязване на това действие е rater 'не хващам, не улавям' (срв. книж. manquer, жарг. louper ), в българския изпускам, в турския - kaçırmak 'изпускам' (букв. допускам да избяга). Те образуват конкретни структури, които независимо от общата си семантика са маркирани по един или друг начин от системата на съответния език и заедно с преносните си значения отразяват различни картини на света. Може да се лансира хипотезата, че в тях се отразяват когнитивни структури, чието формално представяне би оптимизирало процеса по активното им овладяване като чуждоезиково съдържание.

Френският глагол rater, чиято етимологична история идва от prendre un rat 'хващам плъх' (образуван съответно от съществителното rat 'плъх '2 с окончание -er) претьрпява странна семантична конверсия (чиято хронологична процесуалност остава нефиксирана в писмени източници). Навлиза в класическия и в съвременния френски език не с това свое първично значение, а с нереализируемостта на действието по хващането на опасния гризач. По този начин френският израз rater le train има значението 'изпускам (изтьрвавам) влака', тъй като глагольт rater изгубва първоначалното си значение на 'хващам, улавям'. Преносните му значения се свързват с различни прояви на „неуспех“, стигащ и до пълен „провал“. Френският език притежава още два глагола за изразяване на идеята за изпускане на дадено превозно средство: книж. manquer и жарг. louper. Книжовната форма manquer 'изпускам, пропускам' е с ограничена употреба и се съчетава основно с train 'влак' и avion 'самолет': manquer son train $^{3}$ / son avion 'изпускам влака си / самолета си'. Тези изрази са образувани по модела на класическия израз manquer son coche 'изпускам пощенската кола (за превоз на пътници)', който през вековете сьщо загубва това свое пьрвоначално значение и сега означава само 'изпускам шанса си'. Жаргонната

\footnotetext{
${ }^{1}$ В реалната комуникация говорещият кодира изказа си така, че слушащият обикновено да успее да се ориентира в контекстуалната употреба и правилно да интерпретира този тип изказ, без да се замисля за другите възможни тълкувания на смисъла. Проблемът не стои така с изолираната употреба на конкретни изкази. Например „Разсеях се и изпуснах дузпата“ ще остане неразбран, ако няма ясно конфигурирана контекстуалност за слушателя: а) може съдията да се е разсеял и да е изпуснал да свири дузпата; б) може вратарят да не е спасил дузпата; в) може пък нападателят да не е успял да отбележи гол.

2 Произходът на rat се извежда от звукоподражателния корен ratt-, получен от имитацията на звука, който идава животното по време на гризането (вж. TLF).

3 Във френския книжовен стил се срещат фразите Pressons-nous pour ne pas manquer le train 'да се забързаме, за да не изпуснем влака'; Dépêche-toi ou tu vas manquer le train 'Побързай или ще изпуснеш влака'; Je voulais prendre le thé en ville mais craignais de manquer le train 'Бих желал да пия чай в града, но се страхувам, че ще изпусна влака' и др. Глагольт manquer в ежедневието се заменя с rater, а в жаргонна употреба с louper.
} 
форма louper 'изпускам' идва от вторичното значение фр. loup 'пропуск, дефект, грешка'4. Значението ‘изпускам превозно средство' се развива след 1915 г. по модела на louper la commande 'провалям ефекта от дадена заповед, тъй като закъснявам с нейното изпълнение'. В момента фр. louper е жаргонното съответствие на разговорната форма rater 'изпускам (не хващам), 5 .

Българският глагол изпускам идва от съчетаването на представката зз- $^{6}$ с глагола $n y c \kappa a м$, т.е. 'разтварям ръце и давам свобода на това, което държа да извърши свободно движение (по посока на земното притегляне или да се понесе във въздуха)', но той развива и значението ‘пропускам възможността да се възползвам от нещо конкретно'. В действителност, поради закъснение говорещият няма възможност да се възползва от превозното средство, за да стигне от точка $А$ до точка $Б$ и именно тази семантика е в основата на израза изпускам влака. В жаргонната българска реч се среща израза разминавам се с влака, при който значението 'изпускам превозното средство' се постига въз основа на идеята за „провалената среща“7. Архаизиран синоним на изпускам е и глаголът изтървавам, който в съвременния български език е с ограничена употреба (изтьрвавам нощзия влак, изтървавам последния автобус и др.).

В турския език глаголът kaçırmak произлиза от глагола kaçmak с основно значение ‘бягам' и афикса -ır, с който се образува причинителен залог, т.е. глаголът kaçırmak е каузатив на глагола kaçmak. По този начин се постига сложната семантика на идеята за 'допускам да (из)бяга, ставам причина да (из)бяга', която се открива в значенията 'пропускам, не успявам да свърша нещо в определеното време', 'изпускам безвъзвратно, изтървавам (възможност)', т.е. някой предоставя възможност (поради закъснението си) на влака да „избяга“.

Френският и българският език допускат в прагматичен план възможността за двойнствена интерпретация на изразите (прагматична полисемантичност), съдържащи съответно компонентите фр. rater / бълг. изпускам и фр. train / бълг. влак (или влак играчка), докато в турския език това явление не се наблюдава (виж тур. treni kaçırmak). Интересното в случая е, че потенциалността на тази полисемна тенденция е най-силна във френския, намалява в българския поради ограничения характер на актантната валентност и изчезва в турското езиково пространство.

Във френския език речевият изказ j'ai raté mon train 'изпуснах влака (букв. не успявам да уловя/хвана ${ }^{8}$ влака)' може да означава, че „се е забавил по пътя и когато е пристигнал на гарата, влакът вече е бил отпътувал“, но може и да означава че „грозно е нарисувал изображението на влакова композиция“ (фр. rater un dessin 'рисувам лошо’) или че е „лошо се е прицелил и не е уцелил с орьжието си преминаващия влак“ (фр. rater son cible, rater son coup "пропускам, не

\footnotetext{
${ }^{4}$ Първичното значение на фр. loup е 'вълк'.

${ }^{5}$ Все пак фр. rater е с най-висока честотност, за което говори и преводът на американската комедия Ноте Alone 'Сам вкъщи' чрез перифразата Maman, j'ai raté l'avion (букв. Мамо, изпуснах самолета).

${ }^{6}$ Представката из- в състава на глаголи със значение: 1. изчерпване на действието докрай, напр. изкопавам, изоравам, изяждам, избесвам; 2. извършване на действие, насочено отвътре навън до неговия резултат, напр. избягвам, изтласквам и др.; 3. изчерпване на действие, при което обектът добива ново качество, напр. изрусявам, избистрям и др.; 4. извършване на еднократно действие, изведнъж, напр. избръмчавам, иззвънявам и др. (РБЕ).

${ }^{7}$ Срв. бълг. За една бройка се разминахме с опасността.

8 Тук има интересна връзка с българския израз „хващуам влак за някъде“, където семантиката на глагола хващам е много близка с началната семантика на фр. rater 'хващам плъхове'. Срв. също така бълг. вземам влак, самолет, трамвай, автобус, такси, колата си, за да отида някъде, фр. prendre le train, l'avion, le tram, le bus, le métro, un taxi, sa voiture pour se rndre quelque part 'букв. вземам'. На турски език ситуацията е малко по-различна. В този контекст за повечето превозни средства се предпочита употребата на глагола binmek 'качвам се', като се поставя маркер за дателен падеж на думата, обозначаваща превозното средство. Глагольт almak 'вземам, хващам' се използва за наемане и качване в такси - taksi almak 'хващам такси', а в разговорния език се допуска и за някои други видове превозни средства като: treni almak 'хващам влака', otobüsü almak 'хващам автобуса' и др., макар тази употреба да не е придобила широка гражданственост. Също така за разговорния език е характерна и употребата на отрицателна форма на глагола yakalamak ‘хващам, залавям' в смисъл на „успявам да се кача на дадено преводно средство“. Когато акцентът се поставя върху това, че някой е стигнал навреме, за да се качи на дадено превозно средство, тогава се използва глагольт yetişmek 'стигам, пристигам навреме', като думата, обозначаваща превозното средство, получава афикс за датив (например: uçă̆a yetişmek ‘хващам (стигам навреме) за самолета').
} 
уцелвам'). Необходимо е да се отбележи, че съчетаемостта на rater с названия на транспортни средства в този контекст е ограничена, но показателна за правилността на прагматическата интерпретация: rater l'avion 'изпускам самолета', le bus 'изпускам автобуса', le métro 'изпускам метрото', le train 'изпускам влака', son train 'изпускам влака си', le tramway 'изпускам трамвая', le trolley 'изпускам тролея', le trolleybus 'изпускам тролейбуса', le bateau 'изпускам кораба', le bateau-mouche 'изпускам корабчето по Сена', le paquebot 'изпускам парахода', le ferry-boat 'изпускам ферибота', la navette 'шатъла (вид маршрутка)', $\sim l e R E R$ 'изпускам бързото метро', $l e T G V$ 'изпускам тежеве-то (сврьхскоростния влак)'. Може да се употребява с определителен член le/la или с притежателното местоимения son/sa (le train или son train 'влака' или 'влака си', l'avion или son avion 'самолета' или 'самолета си' и др. Но не може да се употреби с char 'танк', véhicule 'превозно средство', locomotive 'локомотив', voiture 'кола', bagnole 'кола', auto 'автомобил' и т.н.).

Българското съответствие на фр. rater son train е изразът изпускам влака. В случая глагольт изпускам е също така многозначен както френския, но обикновено в този транспортен контекст се приема основно прагматическата интерпретация, че говорещият е пристигнал със закъснение на гарата, когато влакът вече е заминал и той не е могъл да се качи на него. За слушателя е явно, че събеседникът не е „разтворил ръце и пуснал да падне на земята детска играчка във формата на влак“, а просто със закъснение се е появил на гарата. За разлика от френския език възможността за двойствена интерпретация е значително по-слаба и обикновено има допълнителни маркери, че става въпрос за изпускане на някакъв предмет (играчка) във форма на съответното превозно средство: изпускам влакчето, самолетчето, корабчето и др. Това се обяснява със спецификата на българската лексикална съчетаемост. В ежедневната речева практика обикновено човек изпуска автобус, влак, самолет (т.е. превозно средство, което има някакво разписание, обективно независещо от волята на говорещия), такси (тьй като се предполага, например, че шофьорьт е чакал известно време и е изгубил надежда, че пьтникьт ще се появи, поради което е отпътувал; или шофьорьт не е забелязал, че към него се е насочил клиент, който иска да се качи в колата му, и е тръгнал да търси други клиенти; възможно е също така да е получил „адрес“ от диспечера за поръчка, която спешно трябва да се изпълни). Към тези транспортни средства, служещи за пряко допьлнение на глагола изпускам трябва да се добавят бус, електричка (ост.), кораб, корабчето, лодката (за разходка), маршрутка, метро, трамвай, тролейбус, ферибот, рейс (разг.), теснолинейка (ост.). Българският език не допуска употребата на изрази от типа на изпускам колата, автомобила, мотора, мотопеда, джета, колелото, велосипеда, лодката, яхтата, танка, БТР-а, трактора, камиона, ТИР-а, ракетата, космическия кораб и други транспортни средства, които самият говорещ привежда в движение и управлява. В българския език глагольт изпускам може да се употреби с членувани съществителни имена, а така също и с възвратно притежателно местоимение (свой/своя/свое/свои) и названието на съответното транспортно средство 9

Турското съответствие на българско-френската идиоматична верига изпускам влака <-> rater son train, е изразът treni kaçırmak. Когато глагольт kaçırmak се използва в значение 'изпускам', отнасящо се за превозно средство (т.е. пропускам / не успявам да се кача на дадено превозно средство, тъй като съм пристигнал на мястото на тръгването му със закъснение без оглед на субективността / обективността на причината за това), той е транзитивен. Името, обозначаващо превозното средство, на което лицето, извършващо действието, не успява да се качи, е в синтактичната функция на определено пряко допълнение (т.е. с акузативен маркер). Възможно е съществителното име, което е название на превозното средство, да бъде във форма за множествено число или за притежание (например: Bütün trenleri kaçırdım. - Изпуснах всички влакове. (букв. Всички влаковете изпуснах.); Trenimi kaçırdım. - Изпуснах влака си. (букв. Влака

\footnotetext{
${ }^{9}$ Изразът изпуснах колата / автомобила / болида си могат да се употребят в значение 'изпуснах контрола (управлението) на превозното средство’ като задължително трябва да се укаже мястото на това действие - изпуснах колата / автомобила / болида / мотора си на влизане във виража / на околоврьстното шосе / на третия километър / на скоростната тангента / при навлизане в кръстовището или при престрояването в другата лента /при навлизане в гарата и т.н.
} 
моя изпуснах. $)^{10}$. Поради семантиката на турския глагол kaçırmak в речевата употребата на израза treni kaçırmak 'изпускам влака' не може да се получи двусмислие, че лицето, извършващо действието, е допуснало да падне на земята влак / влак играчка. В такъв случай би се употребил глагольт düşürmek 'изпускам, изтьрвавам; събарям, свалям', който носи значението, че допускам да падне нещо, което държа, нося или крепя (например: Bebek elinden tren оуuncağını düşürdü. Бебето изпусна влакчето, което държеше. [букв. Бебето ръката си от влака играчка остави да падне.] $)^{11}$. Подобно на ситуацията във френския и в българския език турският глагол kaçırmak ce съчетава с названия на превозни средства, които имат фиксирано разписание, независещо от субективните желания и поведение на лицето, извършващо действието. В тази връзка са допустими съчетания със следните съществителни имена: otobüs 'автобус', dolmuş 'маршрутка', 'параход; кораб', gemi 'кораб', feribot 'ферибот', araba vapuru 'ферибот', araball vapur 'ферибот', servis ( aracl) 'служебен транспорт/превоз' и др. В турския език се допуска употребата на словосъчетанието taksiyi kaçırmak 'изпускам таксито', макар то обикновено да не се движи по фиксирано разписание. В турската речева практика не се регистрират словосьчетания на глагола kaçırmak в значение 'изпускам' (не успявам да се кача на дадено превозно средство, тъй като съм пристигнал на мястото на тръгването му със закъснение) с думи, означаващи следните транспортни средства: araba 'кола', otomobil 'автомобил', motor 'мотор', motosiklet 'мотоциклет', motorlu bisiklet 'мотопед, мопед', bisiklet 'велосипед, колело', kaylk 'лодка', yat 'яхта', tank 'танк', ZPT (zırhl personel taşlyıcı) 'БТР (бронетранспортьор)', traktör 'трактор', kamyon 'камион', TIR 'ТИР', roket 'ракета', uzay gemisi 'космически кораб', uzay mekiği 'космическа совалка', taşıt 'превозно средство' и др. Всъщност всичките указани тук примери са за транспортни средства, които лицето, извършващо действието, задвижва или управлява, при което се вижда ясният паралел с българския и с френския език.

Таблица на френско-българско-турската съчетаемост на глагола изпускам и неговите съответствия във френския и турския език с различни видове превозни средства.

\begin{tabular}{|c|c|c|}
\hline френски & български & турски \\
\hline rater & изпускам & kaçırmak \\
\hline le train & Влака & Treni \\
\hline l'omnibus & пътническия влак & yolcu trenini \\
\hline le train direct & директния влак & direkt treni \\
\hline le rapide & бързия влак & hizli treni \\
\hline l'express & Експреса & ekspresi \\
\hline le RER & - & - \\
\hline le TGV & - & - \\
\hline- & Електричката & - \\
\hline
\end{tabular}

\footnotetext{
${ }^{10}$ Непопулярно е съчетаването на формата за множествено число с афикс за притежание, съответстващ на българските притежателни или възвратни притежателни местоимения, но в разговорния език е допустим (например: Trenlerimi kaçırdım. - Изпуснах влаковете си.). В българския език употребата на словоформата за множествено число на влак в изрази от типа на изпускам влакове се използва само в следните случаи: а) еди-кой си изпусна и двата (трите) влака за деня; б) еди-кой си изпусна всичките влакове за деня (за този ден, за въпросния ден); в) еди-кой си изпусна всичките влакове за София.

${ }^{11}$ В турския език е възможно обаче, особено с някои видове транспортни средства, да се получи омонимно съчетание, което да е със значение 'вземам, открадвам' (например: Babamdan gizli arabayı kaçırdım. Тайно от баща си взех колата. (букв. Баща ми от тайно колата откраднах.); Kaçırdı̆̆ trenle kaza yaptı. Катастрофира с влака, който открадна. (букв. Открадна който влака с катастрофа направи.).

12 Всъщност думата dolmuş буквално означава 'напълнен', тъй като този вид транспорт в Турция обикновено тръгва от началната спирка, след като се събере достатъчен брой пътници, т.е. след като се напълни. Макар да нямат точно разписание, маршрутките се придвижват по относително известни на ползващите ги часове.
} 


\begin{tabular}{|l|l|l|}
\hline \multicolumn{1}{|c|}{-} & Теснолинейката & \\
\hline la navette - & \multicolumn{1}{|c|}{-} \\
\hline le bus & автобуса & Otobüsü \\
\hline \multicolumn{1}{|c|}{-} & служебния автобус & servisi / servis aracını \\
\hline le bus de l'école - & училищния автобус & okul servisini \\
\hline le car - & международния автобус & ülkeler arası otobüsü \\
\hline & междуградския автобус & şehirler arası otobüsü \\
\hline & селския автобус & köy otobüsünü \\
\hline le minibus - & междуселските автобуси & köyler arası otobüsü \\
\hline & бусчето & \\
\hline le métro & минибуса & Minibüsü \\
\hline le funiculaire & маршрутката & Dolmuşu \\
\hline le tramway / le tram & метрото & Metroyu \\
\hline le trolley / le trolleybus & фуникуляра & Füniküleri \\
\hline le ferry-boat & трамвая & Tramvay1 \\
\hline le bateau & тролейбуса & Troleybüsü \\
\hline le bateau-mouche & ферибота & feribotu / araba vapurunu \\
\hline le paquebot & & arabalı vapuru \\
\hline le taxi & кораба & gezi vapurunu / gemiyi \\
\hline l'avion & & Vapuru \\
\hline & парахода & Taksiyi \\
\hline таксито & Uçağ1 \\
\hline самолета & \\
\hline
\end{tabular}

Анализът на ексцерпирания материал показа, че в трите езика 'изпускането на дадено превозно средство' се назовава с транзитивни конструкции: бълг. изпуснах влака, фp. rater le train и тур. treni kaçırmak, като обикновено обектът е в единствено число, тъй като се предполага, че субектьт не може едновременно да пътува с няколко превозни средства. Срещат се обаче и по-сложни случаи, когато обектът е в множествено число. Тази употреба е мотивирана контекстуално от допълнителни маркери: бълг. (тъй като събранието продължсава дълго) изпускам всички влакове за деня, изпускам сутрешните (следобедните / вечерните / ношните) влакове, изпускам влаковете (всичките влакове) за София // фр. (comme la réunion s'est prolongée) j'ai raté tous les trains (ce jour-là), j'ai raté les trains du matin (de l'après-midi / du soir / de la nuit), j'ai raté les trains (tous les trains) pour Sofia // тур. (toplantı uzun sürdüğü için) bütün trenleri kaçırmak (o gün için) '(тъй като събранието продължава дълго) изпускам всички влакове (за този ден)' (букв. събранието дълго продължава тъй като, всички влаковете изпускам (този ден за), sabah (akşam / gece) trenlerini kaçırmak 'изпускам сутрешните (вечерните / нощните) влакове' (букв. сутрин (вечер / нощ) влаковете изпускам), Sofya trenlerini (bütün Sofya trenlerini) kaçırmak 'изпускам влаковете (всичките влакове) за София' (букв. София влаковете (всички София влаковете) изпускам).

В когнитивно-прагматичен план и в трите езика се допуска наличието на различни интерпретации в зависимост от принципа за уместност на речевия акт в конкретната комуникативна ситуация. Извинението, позоваващо се на изпуснато превозно средство, може да породи различни интерпретации: буквално възприемане на информацията (еди-кой си е изпуснал превозното средство и пристига със закъснение); несъгласие с даденото обяснение за закъснението и неприемане на това обяснение като валидно; тревога по отношение на нещата, които са могли да се случат на субекта в очакване на следващото превозно средство; ревност 
(осъдителност, укор и т.н.) по отношение на действията, които субектът е могъл да извърши във времето до пристигането на следващото превозно средство и др.

Съпоставителният валентен анализ показа, че независимо от общата каузалнокогнитивна и вербално-комплементарна синтактична структура запълването на субстантивалната верига не е еднородно в трите езика. Дължината на комбинаторните вериги във трите езика свидетелства за особеностите на съответните езикови картини за света, като основните разлики са свързани с традиционната организация на транспортната мрежа в дадена страна и честота на използване на определен вид транспорт. Те се проявяват по отношение на реалиите и спецификата в назоваване на отделни локални транспортни разновидности. Независимо от различната лексикална комбинаторна наситеност в отделните езици на идеята за 'изпускане на превозно средство поради закъснение на субекта', тя не се явява сериозна пречка в традуктологично отношение. Комбинаторният потенциал в трите езика показва елементи на типологично сходство, независимо от явната разлика в синтактичната организация между българския и френския като представители на индоевропейските езици и турския като представител на алтайското езиково семейство.

Предложеният модел за изследване на сыпоставителната съчетаемост на лексикални елементи, изразяващи идеята за изпускане на превозно средство поради закъснение, може да послужи като модел за преподаване на допустимите сьчетаемости на лексемите в процеса на чуждоезиково обучение и като основа за изготвянето на дву- или многоезични речници с множество примери за правилна употреба на лексиката в речта.

\section{БИБЛИОГРАФИЯ: АТБP (2009)}

\section{БTP (1993)}

Матурана, У. (1996)

\author{
НTРБЕ (1997) \\ РСБКЕ (1955-1959)
}

PБE (1977-)

СТРБЕ (1994)

GR (2017)

GTS (2019)

PL (2017)

PR (2017)

TLF (2004)

Wilson, D., D. Sperber (2012)
Академичен турско-български речник. Добрев, Ив.,В. Великов, И. Хранов, К. Зографов, М. Маринова, М. Йорданова, М. Димитрова, Цв. Цоков (ред.). София: Рива. (Academichen Tursko-Bulgarski Rechnik. Dobrev, Iv., V. Velikov, I. Hranov, K. Zografov, M. Marinova, M. Yordanova, M. Dimitrova, Tsv. Tsokov (Eds.). Sofia: Riva.)

Български тълковен речник. Андрейчин, Л, Л. Георгиев, С. Илчев, Н. Костов, И. Леков, С. Стойков, Ц. Тодоров (ред.). София: Българска академия на науките. (Balgarski talkoven rechnik. Andreychin, L., L. Georgiev, S. Ilchev, N. Kostov, I. Lekov, S. Stoykov, Ts. Todorov (Eds). Sofia: Balgarska academia na naukite.)

Биология и познание. -В: Язык и мышление. Москва, 1996, с. 95 - 142. (Maturana, U. Biology and Knowledge. - V: Yazik i mishlenie. Moskva, pp. $95-142$.)

Нов тълковен речник на българския език. София: Маг '77. (Nov talkoven rechnik na balgarskia ezik. Sofia: Mag '77.)

Речник на съвременния български книжовен език. София: Българска академия на науките. (Rechnik na savremennia balgarski ezik. (Ed. Stoyan Romanski). Sofia: Balgarska academia na naukite.)

Речник на българския език. София: Българска академия на науките. (Rechnik na balgarskia ezik. Sofia: Balgarska academia na naukite.)

Съвременен тълковен речник на българския език. Буров, С., В. Бонджолова, М. Илиева, П. Пехливанова (ред.). Велико Търново: Елпис. (Savremenen talkoven rechnik na balgarskia ezik. Burov, S., V. Bondjolova, M. Ilieva, P. Pehlivanova (Eds.). Veliko Tarnovo: Elpis.)

Le Grand Robert de la langue française. Paris.

Güncel Türkçe Sözlük.

$\leq \mathrm{http}: / /$ www.tdk.gov.tr/index.php?option=com gts\&view=gts $>$

Le Petit Larousse. Paris.

Le Petit Robert. Paris.

Le Trésor de la Langue Française. Paris, 2004.

Meaning and Relevance. Cambridge: Cambridge University Press. 